\title{
Toward a Research Agenda: Building Character Strengths in School Settings
}

\author{
Andrew Sokatch ${ }^{1}$
}

Received: 24 February 2017 / Accepted: 4 March 2017 / Published online: 23 March 2017

(C) Springer Science+Business Media New York 2017

\begin{abstract}
Character strengths matter for long term success, and a growing body of evidence suggests that schools can be powerful places, and teachers powerful agents, by which these strengths are developed in adolescence. The articles in this volume move the field forward in important ways, and lead to a clear research agenda focused on creating testable interventions to build school and classroom environments that will assist young people in growing and leveraging these critical strengths.
\end{abstract}

Keywords Character Strengths $\cdot$ Positive Youth Development $\cdot$ Schools

Research confirms what many already believed they knew intuitively-that character (or social emotional skills, or non-cognitive attributes; the language remains in need of some standardization, and for the purpose of this essay, can be used more or less inter-changeably) matters for long term success. We know that young people who show more "grit" (passion for long term goals) are more likely graduate from under resourced high schools (Eskreis-Winkler et al. 2014), and we know that young children who can delay gratification also have, as adults, better economic and even health outcomes than those who are less able to delay gratification as preschoolers (Mischel et al. 1989). In fact, recent work has suggested that non-cognitive skills, which we can arguably term 'character', account for about half of what

Andrew Sokatch

andrew.sokatch@gatesfoundation.org

1 Bill \& Melinda Gates Foundation, Seattle, Washington, USA matters for positive academic, post-secondary, labor market, and life outcomes for young people (Heckman et al. 2006).

At the same time, we are learning more about the degree to which these skills can be learned in school settings. Long term evaluation of the Perry Preschool program and other high quality early childhood education programs show that the cognitive (tested academic ability) advantages of attendance begin to disappear in early elementary school. However, positive long term life outcomes, including employment, earnings, and decreased involvement in the criminal justice system, are significantly improved, presumably by a set of non-cognitive, or character skills or traits, that are nurtured and developed in high quality preschool programs (Schweinhart et al. 2005). It is notable that these skills and traits, developed in the first years of life, continue to pay dividends through middle age.

Moreover, we are learning that teachers can make a real difference in these skills and traits, and that, perhaps counter-intuitively, the teachers who are adept at leading their students to develop these skills are not the same teachers who are skilled at raising their students' end of year test scores (Jackson 2016). Of critical importance, these teachers who lead their students to large "value add" on noncognitive skills matter for their students, in terms of producing desirable long terms outcome like high school course taking, graduation and college going, as much as the teachers who are good at adding value to the (much more easily measured) skills assessed on end of year standardized tests of math and reading (Jackson 2016). And that means that, at present, we risk failing to find, study, reward, and replicate half of what matters for life success, and can be learned at school, and half the teachers who are setting their students on paths to a life time of success.

It is, therefore, the perfect time for this set of articles. All these articles move the field forward and, as a cohesive 
whole, they make a significant contribution to how we can conceive of the development of character through adolescence. They also suggest a set of questions for future investigation.

First, these articles suggest a need for new research methodologies that would allow for analyses of how individuals react to interventions or experiences based on their particular situations in the moment. Advances in technology suggest possible avenues for promising practices. Rather than relatively long surveys that ask people to reflect on beliefs or skills one or two time over the life of a study, one can imagine short, text message based, in the moment, data collection technologies that capture evidence, and also context: not just how a subject is perceiving an experience or self-rating themselves on a skill, but where they are, what they are doing at the moment, and with whom. Such rich data would allow for further understanding of not only how character develops over the life course, or how individuals construe challenges, but how, specifically, certain situations and environments impact the interpretation of experience and the development of character. Several recent promising articles have employed these techniques, which seem to hold real promise to move the field forward (Meindl et al. 2015; Bollich et al. 2016).

Most importantly, we are left with the question of what, exactly, one should do. Teachers and parents believe developing these skills is important. New federal regulations as part of the Every Student Succeeds Act (ESSA) open the door for states to include non-academic measures as part of their high stakes accountability schemes, and a consortium of school districts educating over 1,000,000 students is currently is being held accountable through their NCLB waiver for measures of SEL. Beyond the vexing and non-trivial questions about measurement and the wisdom or folly of including these sorts of traits in accountability schemes, (Duckworth and Yeager 2015), the current state of research and practice raises critical question about what, exactly, teachers and schools should be doing to build these skills in their students, what the appropriate "scope and sequence" of these overlapping strengths and traits might be, and how they interact with, and are informed by, the environments in which children and adolescents find themselves.

Can the processes that led to the positive outcomes that Seider et. al. found be recreated in other schools, or do they demand the kind of intentional school and culture creation, and possibly student, parent, and teacher self-selection, that occurred in the schools studied? Can the intellectual virtues that Baehr proposes be infused in a meaningful and lasting way into existing school environments? What can schools do to help proactively develop grit, purpose, resilience, and other traits in young people while respecting and even leveraging the diversity of experience and environments that Malin et al, Callina et al, and Jayawickreme, Brocato \& Blackie so helpfully point out are inextricably tied to the dynamic practice of adolescent development.

Can we understand more about the variation within these studies-do particular teachers in particular schools have better outcomes for developing character in their students? And, if so, can we learn more about what distinguishes them from their less impactful peers?

In short, these articles call forth a powerful new research agenda: namely, the work of creating testable interventions for classrooms, teachers, schools and districts to truly inform practice and ensure that more young people develop and leverage these skills that we now know matter so much for long time life success. We must commit ourselves to finding and replicating scalable ways to create school and classroom cultures in which the virtues that this set of articles show us are so critical to healthy development and successful academic attainment can inform, and change, the ways in which schools do their work.

\section{Compliance with Ethical Standards}

Conflict of Interest The author declares that he has no competing interests.

\section{References}

Bollich, K. L., Doris, J. M., Vazire, S., Raison, C. L., Jackson, J. J., \& Mehl, M. R. (2016). Eavesdropping on character: Assessing everyday moral behaviors. Journal of Research in Personality, $61,15-21$.

Duckworth, A. L., \& Yeager, D. S. (2015). Measurement matters: Assessing personal qualities other than cognitive ability for educational purposes. Educational Researcher, 44(4), 237-251.

Eskreis-Winkler, L., Duckworth, A. L., Shulman, E., \& Beal, S. (2014). The grit effect: Predicting retention in the military, the workplace, school and marriage. Frontiers in Personality Science and Individual Differences, 5(36), 1-12.

Heckman, J. J., Stixrud, J., \& Urzua, S. (2006). The effects of cognitive and noncognitive abilities on labor market outcomes and social behavior. Journal of Labor Economics, 24(3), 411-482.

Jackson, C.K. (2016). What do test scores miss? The importance of teacher effects on non-test score outcomes. NBER working paper 22226.

Meindl, P., Jayawickreme, E., Furr, R. M., \& Fleeson, W. (2015). A foundation beam for studying morality from a personological point of view: Are individual differences in moral behaviors and thoughts consistent? Journal of Research in Personality, 59, 81-92.

Mischel, W., Shoda, Y., \& Rodriguez, M. L. (1989). Delay of gratification in children. Science, 244, 933-938.

Schweinhart, L. J., Montie, J., Xiang, Z., Barnett, W. S., Belfield, C. R., \& Nores, M. (2005). Lifetime effects: The highscope perry preschool study through age 40. (Monographs of the highscope educational research foundation, 14). Ypsilanti, MI: HighScope Press. 